\title{
Using listening journals to raise awareness of Global Englishes in ELT
}

\author{
Nicola Galloway and Heath Rose
}

Background to the study

The changing context of English usage around the world
With the increasing use of English as a Lingua Franca (ELF), it is no longer appropriate to associate English purely with 'native-speaking' nations, but with a global community of users. This article reports on the use of listening journals in ELT to expose students to global Englishes (GE), a field that reflects the current global use of English. These journals served as a pedagogical task, and as a research instrument that involved the analysis of 108 journals consisting of 1,092 reflections on GE exposure. The results highlighted students' current use of English, the impetus behind the selection of material for the listening journal, and their reflections on this exposure. The study not only shows a benefit in using listening journals to raise awareness of $G E$ but also highlights limitations, including the reinforcement of stereotypes and a tendency to reflect on attitudes towards different varieties of English rather than how successful ELF communication is achieved.

The unprecedented internationalization of the English language and the increasing use of English as a Lingua Franca (ELF) around the world have resulted in a drastically changed sociolinguistic landscape of English. The field of global Englishes (GE), an inclusive research paradigm and ideology, brings together World Englishes (WE), where researchers identify and codify national varieties of English, and ELF, where researchers examine the use of English among speakers from different language backgrounds. Despite having a differing focus, what WE and ELF have in common is the focus on the diversity associated with the global spread of English, which strongly questions the relevance of native English speaker (NES) norms for all ELT learners. Recent years have witnessed a growing interest in the pedagogical implications of GE-related research and a number of proposals for change to ELT practice have been suggested, which include calls to increase students' exposure to the diversity of English in order to better equip them to use ELF in a variety of contexts. However, despite calls for change, discussion remains largely at the theoretical level and there is both a scarcity of research at the practical level and a scarcity of resources for those who wish to act on such proposals and bring a 
Making ELT more relevant more GE perspective into the classroom. In an attempt to address this gap in classroom-based research, this study aimed to investigate the application of recent pedagogical proposals for change.

ELT in many contexts all too often continues to view English as a static, monolithic entity, placing emphasis on the NES. The NES continues to be used as a yardstick of competence in the language, despite the fact that English has now become a global language. This is also unfortunate given the flourishing research within the GE paradigm, which highlights the irrelevance of NES norms for those who are likely to use ELF in the future. However, discussion of the pedagogical implications of GE research is becoming more commonplace at international conferences, and has also gradually seeped into language teaching journals, including recent articles in ELT Journal by Suzuki (2OII), Baker (2OI2), Cogo (2OI2), and Jenkins (2OI2). There are also an increasing number of books on the teaching of English as an international language (for example Alsagoff, McKay, Hu, and Renandya 20I2; Matsuda 2OI2) and the pedagogical implications of WE (for example Kirkpatrick 2007).

The main focus of these discussions is on the need to move away from a focus on NES norms, towards a more GE-oriented view. Proposals (cf. Galloway and Rose 2015) include the need for:

- more exposure to the diversity of English

- more value placed on learners' multilingualism

- increased exposure to ELF communication

- the development of communication strategies to help students use ELF with an aim of mutual intelligibility and mutual understanding.

ELF research shows how, used as a contact language in fluid settings, English speakers make use of their multilingual repertoires and use various pragmatic strategies such as repetition, paraphrasing, and code-switching to achieve successful communication. Cogo (2009), for example, notes the use of accommodation as a key pragmatic strategy, which allows 'their exchanges to be more intelligible than if they had referred to standard native-speakers' norms' (ibid.: 257). Thus, exposure to ELF communication, as well as practice using it, is seen as being more valuable than adhering to one rigid code. Kumaravadivelu (2OI2) calls for an epistemic break in ELT, stressing the need to break free from the dominance of the NES episteme and norms. It is clear that this is something that is needed. However, few researchers have examined the implementation of proposals for change and, with limited materials available, it is unclear how teachers who wish to adopt a more 'global', as opposed to 'NES dominated', approach to ELT can progress.

There have been advances in recent years, and some researchers have begun to investigate the incorporation of GE into the classroom (Baker op.cit.; Galloway 2013). The present study aims to build on previous research, as well as to investigate further the proposals for change outlined above, focusing on one GE-oriented classroom practice at a Japanese university involving a listening journal task. It is important to 


\section{The study}

The context

The students

Why Japan?

Research questions point out here that a GE-orientated approach to ELT does not mean the teaching of ELF, or of replacing one model with another. ELF research is not focused on the establishment of a 'variety'. A GE approach to ELT is one which embraces diversity, exposes students to the current use of English worldwide, and provides opportunities to use ELF, as well as reflect on it (cf. Galloway and Rose op.cit.).

The study represents an examination of the use of listening journals as an autonomous learning tool to introduce students to the diversity of English in order to help address the theory/practice divide in the field of GE.

The journal was introduced in four GE content courses for third- and fourth-year students at a private Japanese university. The course was developed based on the proposals put forward in the literature, with the aim of raising students' awareness of GE (the spread of English, the associated diversity in use of English, ELF usage, etc.) and also their confidence as 'legitimate' speakers of an international language. The course was taught twice a week for $\mathrm{I} 3$ weeks by one of the researchers over four consecutive university semesters.

In all, ro8 students were involved in the study, which included all students who completed the GE courses, averaging 27 students per class. The listening journal was a pedagogic activity, and students listened to speakers from a range of English-speaking backgrounds or listened to ELF interactions for an average of ten minutes each week. They were asked to reflect on what they heard (see Appendix I for guidelines), noting down the speakers' nationality, the reasons for their choice, and also to make extended reflective comments. Some students also chose to reflect on their real-life ELF from their daily lives.

Japan was chosen as a research context for a number of reasons. While English is not afforded official status, as with other traditional 'English as a foreign language' countries in Kachru's (1992) expanding circle (EC), English is increasingly used within the country in educational, business, and social domains, clearly taking on more than a mere 'foreign' status. However, despite a growing awareness of the role of ELF in Japan's language policy, NES norms continue to be seen as the model. NES norms are used as a yardstick for tests; and NESs, who are seen as 'ideal' teachers, continue to be hired around the country in a move to make classrooms more communicative. Jenkins (20I2) notes that she was first made aware of ELF inside an ELT classroom. Similarly, our interest in the need for change in ELT also stems from our own experiences teaching in Japan, where, 'encouraged' to teach towards NES norms, we became interested in the mismatch between our classroom focus and our students' needs.

The present study aimed to answer the following research questions:

1 When given a choice, what type of Englishes and ELF interactions do students prefer to listen to, and why? 
Data collection instruments

\section{Results}

Data analysis
2 What were students' reported reactions to what they listened to?

3 How did the students evaluate the listening journal activity as a pedagogical tool during the course?

The listening journals served a dual purpose: a pedagogical tool and a research instrument. Dörnyei (2007: 157) argues journals are a powerful research tool to provide an 'insider account' where 'participants become co-researchers as they keep records of their own feelings, thoughts or activities'.

Firstly, due to a lack of resources, the study turned to internet-based resources as well as making digital audio and video recordings of speakers from different countries and ELF exchanges available in the university's library. Students were also given a list of possible resources, including online corpuses of English, although ultimately many students found their own online or personal sources. Guest speakers from various countries were invited and students were encouraged to reflect on ELF interactions that they had already taken part in. Thus, the listening journals provided a way for students to self-direct their own learning, and an opportunity to increase their exposure to the diversity of English.

In addition to the listening journals, ten interviews were conducted with students at the end of the course, to examine attitudes toward the GE course in general, of which references to the listening journal task were extracted for the purposes of this study. The interview questions formed part of a larger study on the GE course in general, and can be found in Galloway (op.cit.). The interviews were transcribed using the conventions shown in Appendix 2.

The listening journals were numbered and the data were coded according to the country of origin of the speaker the student listened to. For ease of initial analysis, these countries were grouped according to Kachru's (op.cit.) three concentric circles of WE: the inner circle (IC), the outer circle (OC), and the EC. The authors acknowledge the limitations of grouping Englishes in this way (cf. Jenkins 2009; Galloway and Rose op.cit.), which include the focus on geographic and historic factors, the focus on colonial history, the failure to capture the sociolinguistic uses of English today, the assumption of a monolithic standard, and the problems associated with categorizing pidgins and creoles. Nevertheless, this model has done a lot to raise awareness of the diversity of English and is widely understood; it is thus a useful classification for the purposes of this study.

Both researchers familiarized themselves with the data, agreed on emerging key topics, and coded the data using a mixture of conceptdriven and data-driven coding, meeting regularly to discuss the data analysis process. The quantification of data was used only to identify prominent topics and to gain an initial impression of students' responses, although such frequencies provided insights and highlighted patterns. From the io8 journals, I,092 entries were calculated, averaging ten per student, and 200 of these involved ELF exchanges. 
Interviews were used as a secondary source and, while data analysis followed the same stages as outlined for the listening journals, the interviews were treated as a new data set, and thus different themes were identified and many new codes were created.

Research question 1: students' choice of English speakers
TABLE 1

Students' choices by country grouped into IC, $\mathrm{OC}$, and $\mathrm{EC}$
Initial analysis examined the types of speaker showcased in the material listened to (or the ELF exchange) by the students. The results are summarized in Table I.

Interestingly, within the IC, the highest number of speakers was from the United Kingdom followed by Australia and Canada. Only 33 American speakers were chosen, which may have been due to an overexposure to American English as the prominent model in the Japanese education system, thus prompting students to explore other English varieties. In terms of specific national varieties, following UK Englishes, results saw Japanese English and Indian English eclipse other native English (NE) varieties, showing a clear interest in Englishes outside of the IC. As Table I shows, 459 speakers from the EC were chosen, and in particular OC and EC Asian Englishes tended to rank highly, indicating the students' interests in listening to the English used by speakers in their surrounding geographic area. Thus, the listening journals provided the opportunity to listen to a range of speakers from around the world, and when given the choice, NE was not their first choice.

As Table 2 shows, reasons given for choices were numerous.

'Familiarity' featured heavily as a reason, which included interest due to previous contact with the variety of English or nationality of the speaker, for example through classroom models, teachers, friends, previous holiday experiences, music, and movies.

\begin{tabular}{lrlrlr}
\hline IC & & OC & & EC \\
\hline United Kingdom & 145 & India & 80 & Japan & 85 \\
Australia & 65 & Singapore & 43 & China & 50 \\
Canada & 46 & Philippines & 21 & France & 44 \\
Ireland & 39 & Jamaica** & 13 & Taiwan & 33 \\
United States & 33 & Malaysia & 10 & Italy & 31 \\
New Zealand & 25 & Kenya & 10 & Korea & 28 \\
South Africa* & 14 & Nigeria & 3 & Germany & 18 \\
& & Bangladesh & 3 & Spain & 16 \\
& & Other & 3 & Russia & 15 \\
& & & & Vietnam & 14 \\
& & & & Thailand & 13 \\
& & & & Swexico & 12 \\
& & & & Switzerland & 11 \\
& & & & Sri Lanka & 9 \\
& & & & Brazil & 8 \\
& & & Other & 7 \\
& & & & TOTAL EC & 459 \\
\hline
\end{tabular}

Note: *These could be classified as IC or OC 
TABLE 2

Coding frequencies for reasons for choice

\begin{tabular}{llc}
\hline Tree code & Code & Frequency \\
\hline Familiarity & Classroom model/teacher's nationality & 270 \\
& Friends & 140 \\
& Familiar (unspecified) & 103 \\
& Movies & 87 \\
& Music & 27 \\
& Unfamiliar/difficult & 27 \\
& Holiday & 26 \\
& Perceived familiarity (Asian) & 18 \\
& Family & 2 \\
\hline Stereotype & Stereotype & 60 \\
\hline Usefulness & Perceived usefulness & 40 \\
\hline Integrative & Interested & 179 \\
motivation & Cultural interest & 18 \\
\hline Other & No reason given or random find & 86 \\
\hline
\end{tabular}

Several students also related their choice to 'unfamiliarity', using the listening journal to listen to unfamiliar Englishes, or those they had perceived as 'difficult' to understand. They also used the journals to reflect on previous experiences when they had had difficulty understanding a speaker and to develop skills they could use if they encountered such difficulties again. This finding concurs with studies that show familiarity to be an important influence on the formation of attitudes, such as in Jenkins's (2007: I82) study where a Japanese student-teacher noted that Japanese people were so accustomed to American English that other accents sounded 'unfamiliar'. For an overview of English language attitudes, see Jenkins (ibid.) and Galloway and Rose (op.cit.).

In addition to familiarity, general interest or cultural interest was important, such as, 'I am just curious what people in Thailand sounds like'. Students also indicated an awareness of ELF usage: 'There are many languages in India and English is a common language there. I'm interested in Indian English because I want to know how Indian people pronounce their accent'.

Perceived future usage of the language was also listed as a reason, particularly in their future careers, highlighting the importance of future communities of practice. Comments included 'We are in the age of globalism, so there are many opportunities to speak with Indian people in Japan at [the] workplace. That is the reason that I chose this'. Interview data supported the notion that students used the listening journals to familiarize themselves with Englishes most salient to their perceived future needs.

Research question 2: students' reaction to the listening journal material
Reflections mainly centred on attitudes to varieties of English, even though the comment section in the listening journal had asked students to explore a wider range of topics for reflection. This was probably due to most students choosing varieties of English (892 entries), rather than ELF interactions (200 entries), and thus reflective comments lacked an examination of ELF interactions and the communicative skills used by the speakers. The listening journal seemed to have the opposite intended pedagogical effect on raising positive awareness of the 
diversity of English, and instead reinforced existing stereotypes about the ownership of English, NE, and non-native English (NNE).

In the student reflections, 85 comments referred to a belief in native ownership of the language, and NE was described as 'correct', 'clear', 'easy', 'smooth', 'fluent', 'natural', and 'perfect', unlike NNE, which was described as 'strange', 'unique', 'difficult', 'uncomfortable', 'not cool', 'strong accent', 'couldn't catch', 'incorrect', 'flat', and 'not fluent'. English proficiency was clearly measured against NESs, the so-called 'owners' of the language. Most of the speakers from the OC and EC were multilingual, but it was their closeness to native proficiency that was examined by the students. Moreover, NES proficiency was closely associated with intelligibility, and students not only judged an intelligible accent as being close to a native one, but were also more positive towards it.

The comments also revealed a hierarchy within the IC, with American English at the top. American English was the 'standard', and the preferred yardstick to measure English proficiency. Sixty-five comments made direct comparisons to American English, for example: 'I listened to British English. It is different from American English. I believe that American English is standard English. Many English speakers use American English'. This was also evident in comments referring to a multilingual German businesswoman, who gave a presentation at the university, and was noted to have 'perfect American English' by several. The German woman gave numerous accounts to the students of her successful use of ELF in a myriad of contexts with people from various lingua-cultural backgrounds. Despite being multilingual and an experienced ELF user, it is unfortunate it was only her 'perfect' American accent that was admired in student comments.

In comparison to NE, references to NNE were largely negative, even though earlier comments indicated exposure to NNE was seen as a positive experience. One thousand, nine hundred and ninety negative comments were made in total relating to unfamiliarity (36), a difference to the perceived 'standard' (286), vocabulary (37), pronunciation (I,098), speed (I75), grammar (55), and intelligibility (303). Several directly compared Japanese English with American English, highlighting negative evaluations of the English spoken in Japan. American English is the yardstick with which they evaluated Japanese English. Other comments revealed Japanese speakers who sounded like a NES were clearly admired, especially if 'no one could tell' their Japanese identity from their speech alone.

Research question 3: Although journal entry reflections on NNE appeared to highlight student reflections on the listening journal task negativity, the listening journal task brought these attitudes to the surface, allowing them to be discussed in the class. The interviews with students at the end of the GE course showed a change in opinion, perhaps due to time for reflection on the task. For example:

I know, but I want to continue kind of listening journal to each other (.), I will listen to various English and, eh (.) like, the first time 
I listened to like INDIAN, or RUSSIAN, I feel 'IS IT ENGLISH?' or something like that (.) @, but ...... after I listen to some English many times, I became to like them (.) because they have some very (.) characteristic parts.

The listening journal provided an opportunity to listen to a number of Englishes for the first time, and the emphasis on 'IS IT ENGLISH?' indicates a previous stereotype that English is only spoken by NESs. The listening journal helped the students challenge preconceived stereotypes and exposure was proposed to aid future comprehension.

The listening journals also highlighted students' awareness of the use of ELF worldwide, and this was referred to in 40 comments. As one student noted,

As a common language, English should be clean? Exact?

Nowadays many people from all over the world use English during communication. But British English and American English are often used, and people tends to think they are common language. Even though there are a lot of English in the world. You can't decide which is common language. All of those English are common languages, so you don't have to care about you pronunciation is like Japanese or Chinese, etc. You have to be confident when you talk English in the world.

Thus, for this student, the listening journal provided the opportunity to reflect on the existence of 'standard' English. Interview data also supported a notion that an awareness of ELF had been raised due to the listening journal task. One noted the following:

It was GOOD EXPERIENCE to hear about English like, I have (.), have heard EUROPEAN English in listening journal, so (.) maybe (.) if I DIDN'T take this class I DIDN'T know that English is (.), English is, English have many variety, so maybe it was good opportunity ... ... it's like positive as a Lingua Franca, $\mathrm{mm} \mathrm{mm}$, so like English is as a Lingua Franca so (2) if (.) I (.) went to, to Denmark or Finland (I), they speak their OWN LANGUAGES and but (.) I don't know, know their own languages, so it's USEFUL to communicate with ENGLISH.

This stress on 'GOOD EXPERIENCE' shows that she found the class useful and her specific mention of the listening journal shows she thought it was a helpful tool for future communication.

Discussion and conclusion
The results of this study show that students were interested in listening to and communicating with speakers from diverse lingua-cultural backgrounds. Despite the dominance of IC and American English in Japanese ELT, students were interested in the EC and also the OC, although these were often compared to NE, especially American English. Furthermore, with 200 ELF experiences, the listening journals have highlighted the current opportunities for ELF usage within 
traditional 'EFL' contexts, where English is clearly becoming more than a 'foreign' language.

While the listening journals proved to be a useful pedagogical tool to expose students to diverse Englishes, it was less successful in having them reflect on ELF interactions, and develop strategies they could use for more effective communication (although much of this was done on the course using the journal as a springboard for discussion). The task also caused some students to focus on varieties of English, which brought their own stereotypes and prejudices to the surface. However, the end-of-course interviews indicated that prolonged exposure over the semester caused reflection on, and re-evaluation of, these stereotypes. The researchers suggest that for future studies and classroom practices, the guidelines for implementing a listening journal task be revised to place more focus on ELF interactions and less on the notion of varieties of English. A shift in focus would also better reflect the fluidity of ELF, which challenges traditional notions of 'variety' and geographically defined 'communities'. Such guidelines should also encourage students to choose a variety of spoken genres, since certain genres (for example conversations) are more likely than others (for example one-way news broadcasts or talks) to showcase the use of ELF communication strategies such as accommodation.

With careful guidance, listening journals can be a useful tool to show that mutual intelligibility is more important than native-like proficiency, and may help expose students to shared interactional practices employed by ELF speakers. Also, increased exposure to the diversity of English can encourage students to see themselves as competent multilingual English speakers, not as inferior NNE speakers.

However, it is important to reiterate Jenkins's (2012: 492) comment that we are not prescribing certain pedagogical recommendations for all, nor do we believe 'it is our place to tell teachers what to do'. However, it is important to raise teachers' awareness of the need to re-evaluate ELT practices in light of the changing demographics of English, and needs analysis is crucial in this process. Jenkins (ibid.) emphasized the need to provide students with choice, and we believe that the listening journal may be one useful tool through which to offer such choice. While this may be NE for some, learners can be made aware of alternatives.

Final version received February 2014

\section{References}

Alsagoff, L., S. L. McKay, G. Hu, and W. Renandya (eds.). 20I2. Principles and Practices for Teaching English as an International Language. New York, NY: Routledge.

Baker, W. 20I2. 'From cultural awareness to intercultural awareness: culture in ELT'. ELT Journal 66/1: 62-70.
Cogo, A. 2009. 'Accommodating difference in ELF conversations: a study of pragmatic strategies' in A. Mauranen and E. Ranta (eds.). English as a Lingua Franca: Studies and Findings. Newcastle upon Tyne: Cambridge Scholars Publishing. Cogo, A. 2012. 'English as a Lingua Franca: concepts, use, and implications'. ELT Journal 66/1: 97-105. 
Dörnyei, Z. 2007. Research Methods in Applied Linguistics. Oxford: Oxford University Press.

Galloway, N. 20I3. 'Global Englishes and English language teaching (ELT) — bridging the gap between theory and practice in a Japanese context'. System 4I/3: 786-803.

Galloway, N. and H. Rose. 20I5. Introducing Global Englishes. Abingdon: Routledge.

Jenkins, J. 2007. English as a Lingua Franca: Attitude and Identity. Oxford: Oxford University Press.

Jenkins, J. 2009. World Englishes. A Resource Book for Students (second edition). Abingdon: Routledge.

Jenkins, J. 2012. 'English as a Lingua Franca from the classroom to the classroom'. ELT Journal 66/4: 486-94.

Kachru, Y. I992 'Culture, style, and discourse: expanding phonetics of English' in B. B. Kachru (ed.). The Other Tongue. Urbana, IL: University of Illinois Press.

Kirkpatrick, A. 2007. World Englishes: Implications for International Communication and English Language Teaching. Cambridge: Cambridge University Press.

Kumaravadivelu, B. 2012 'Individual identity, cultural globalization, and teaching English as an international language: the case for an epistemic break' in L. Alsagoff, S. L. McKay, G. Hu, and
W. Renandya (eds.). Principles and Practices for Teaching English as an International Language. New York, NY: Routledge.

Matsuda, A. 2012. Principles and Practices of Teaching English as an International Language. Bristol: Multilingual Matters.

Suzuki, A. 20II. 'Introducing diversity of English into ELT: student teachers' responses'. ELT Journal 65/2: $145-53$.

\section{The authors}

\section{Nicola Galloway lectures in TESOL at The}

University of Edinburgh, including a postgraduate course on Global Englishes. Her research interests are in the pedagogical implications of the spread of English as a global language. She is co-author of the book Introducing Global Englishes (Routledge 20I5) with Heath Rose.

\section{Email: nicola.galloway@ed.ac.uk}

Heath Rose lectures in Applied Linguistics and ELT at Trinity College Dublin, including a postgraduate course on second language teaching. Before this, he worked as a language teacher for 15 years in Japan and Australia. His recent publications include articles in Modern Language Journal, Applied Linguistics, and Foreign Language Annals.

Email: heath.rose@tcd.ie

\section{Appendix 1}

An abridged version of listening journal guidelines
1 To be completed once a week.

2 Spend ten minutes listening to a speaker(s) from a particular country or area, or an ELF exchange. Possible sources (CDs, online corpora, online media) are provided, or you can find your own.

3 Record details and comments in the journal below.

\begin{tabular}{llll}
\hline $\begin{array}{l}\text { Date and time } \\
\text { (Minimum ten } \\
\text { minutes) }\end{array}$ & $\begin{array}{l}\text { Speaker's } \\
\text { name and } \\
\text { nationality }\end{array}$ & $\begin{array}{l}\text { Reason for } \\
\text { choice (3-4 } \\
\text { sentences) }\end{array}$ & $\begin{array}{l}\text { Comments (six to ten sentences) } \\
\text { on observations in grammar, } \\
\text { vocabulary, pronunciation, } \\
\text { pragmatics, (un) intelligibility, } \\
\text { possible reasons for your } \\
\text { reactions/attitude }\end{array}$ \\
\hline
\end{tabular}


A sample of sources provided to students

Websites

CDs

Library sources

Individual sources
The Voices Recordings: http://www.bbc.co.uk/voices/

International Dialects of English Archive (IDEA): http://web. ku.edu/ idea/

The Audio Archive: http://alt-usage-english.org/audio_archive.shtml

The Speech Accent Archive: http://accent.gmu.edu/browse_language. php?function=find\&language=english

International Corpus of English: http://ice-corpora.net/ice/sounds.htm

Vienna-Oxford International Corpus of English: http://www.univie. ac.at/voice/

Kirkpatrick, A. 2007. World Englishes: Implications for International Communication and English Language Teaching. Cambridge: Cambridge University Press.

Recorded presentations/conversations/interviews of a variety of speakers.

Students on campus; teachers; friends; co-workers; and TV and online media.

\begin{tabular}{ll}
\hline [Inaudible segment] & Inaudible portion \\
(overlapping) & Overlapping speech \\
CAPS & Emphatic stress ('I' and acronyms are underlined) \\
$()$. & Pause of less than a second \\
$(3)$ & Approximate length of pause in seconds \\
$:$ & Length (repeated to show greater length) \\
$@$ & Laughter \\
$\ldots$ & Author's gaps \\
\hline
\end{tabular}

